\title{
STUDY ON THE EFFICIENCY IN SETTING UP A MOBILE VEHICLE INSPECTION STATION
}

\author{
Sergey Repin¹, Vladimir Golovko², Sergey Evtyukov³ \\ 1,2,3 Saint Petersburg State University of Architecture and Civil Engineering \\ 2-ya Krasnoarmeiskaya st., 4, St. Petersburg, Russia \\ ${ }^{1}$ repinserge@mail.ru
}

\begin{abstract}
The paper analyzes the commercial feasibility of setting up mobile stations to provide people living in hard-to-reach areas with a service of state technical inspection (STI). An analysis of the application efficiency is carried out under conditions of significant territorial dispersion of sites to check the vehicle technical status in the Komi Republic. The rationale behind the efficiency can be expressed through a rate-of-return chart and results of the feasibility study on the operation of a mobile state technical inspection station, carried out in the Mathcad environment. Recommendations are given to reduce the costs and increase the profit from carrying out STI under specific competitive market conditions.
\end{abstract}

\section{Keywords}

Revenue, costs, rate of return, mobile station.

\section{Introduction}

State technical inspection (STI) allows improving significantly the technical condition of vehicles, reducing thereby the chance of road accidents. However, under conditions of significant territorial dispersion of sites to check vehicle technical status, for example, in the Komi Republic and in other regions of the Far North of the Russian Federation, it is difficult to provide the public with a service of STI (Caron, Mills, 2012; Zeng, Zhang, 2009). One way to solve this issue deals with setting up a mobile STI station. The rationale for the commercial feasibility in setting up those facilities is given in the article.

One of the recently developed methods of economic research, i.e. the marginal analysis, was used to analyze the efficiency of mobile STI stations; this analysis allows presenting results of commercial activity in a visual format and enables managers having no special education to take economically-balanced decisions on the company development.

Let us consider the terms used throughout the paper.

\section{Mobile STI station}

The mobile station (MS) to hold state technical inspection $(\mathrm{STI})^{1}$ is designed to provide services to owners of private cars and to companies on carrying out instrumental state technical inspection and generating a documented opinion on the technical status of vehicles under conditions of significant territorial dispersion of sites to inspect vehicles (Rubin et al., 2019). This situation is typical for regions having low population density, for example, for the Komi Republic, when it is economically inexpedient to set up stationary STI stations in small 
settlements, and car owners have to spend a lot of time to reach a site of obligatory technical inspection.

Efficiency. In the general case, efficiency is considered as a ratio of the operating result to the amount of resources consumed. From the economic standpoint, the efficiency indicator can be expressed through the rate-of-return level that is determined as the percentage ratio of the profit generated by sales of products to the production cost ${ }^{2}$ :

$$
R=\frac{S P}{C} \cdot 100
$$

where $R$ - rate-of-return level, \%; $S P$ - sales profit (RUB); $C$ - production cost (RUB).

Marginal analysis (MA) is an analysis of the ratio of the volume of products manufactured (services rendered) to the production cost and profit on the basis of forecasting the level of those values under given constraints (Azriliyan, 2004). The term "marginal" comes from the word "margin", which, in our case, represents the difference between the price and the cost of the service provided.

\section{Main part}

The margin analysis deals with dividing costs into fixed (or, more precisely, into semi-fixed costs as their value depends on the service life of the production equipment) and variable costs. Fixed costs are costs, the total amount of which does not change when the volume of products or the scope of services is altered. This group includes the following: depreciation of fixed assets; salaries and wages; depreciation of intangible assets; rent; expenses on maintaining buildings, premises; services provided by third parties; expenses on personnel training and development; expenses having a non-capital nature dealing with technology improvement and production management; deductions to the repair fund; deductions for compulsory insurance of property and other types of expenses. A significant part of semi-fixed costs comprising the machine-hour cost of equipment operation is expressed in the form of overheads. These costs actually represent production asset ownership costs.

The total of variable costs changes proportionally to the volume of the output product or to the scope of services rendered. This group includes the following: transportation costs, expenses on maintenance and repair of production equipment, fuel and lubricants, power consumed in production processes (Ratheesh, Vetrivelan, 2019).

The main category of the marginal analysis deals with the marginal profit which is represented by a difference between the income from selling company products and variable costs. The income implies proceeds received by an enterprise from selling products (without VAT).

The equation of the enterprise gross marginal profit consists of two main indicators: sales proceeds and variable costs. Below is an equation to calculate the efficiency of the whole enterprise (Zhdanov, 2015):

\footnotetext{
2 In the case considered, production means the number of conducted STI sessions.
}

Marginal profit $=$ Revenue - Variable costs

In addition to calculating the marginal profit/income for the whole production volume, the marginal profit should be estimated for each product type. The marginal profit for each product type is calculated as a difference between the sales/distribution price and its production cost:

\section{Marginal profit for the product type $=$ Price - -Production cost}

The calculation of the marginal profit for each product type makes it possible to exclude economically unprofitable products (Dotzler et al., 2018).

Let us consider Figure 1 to better understand the place occupied by the marginal profit in the enterprise profit system. The marginal profit is the second most important parameter following the sales proceeds (without VAT); the value of the marginal profit directly affects the size of operating and net profit.

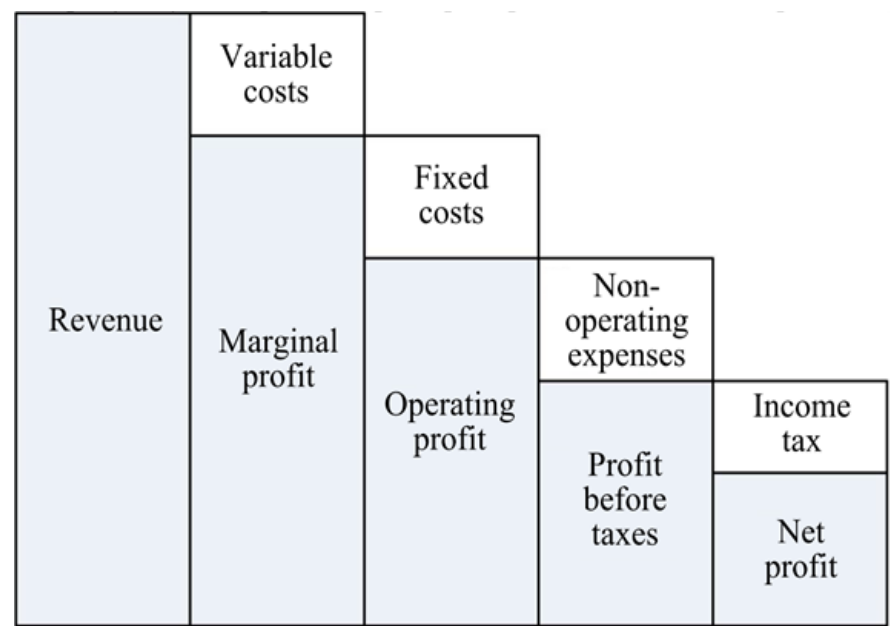

Figure 1. Enterprise profit structure (Zhdanov, 2015)

The analysis of the marginal profit involves resolving the following issues:

1. minimum allowable prices to distribute products (render services) at a given production volume and variable and fixed costs;

2. estimating the break-even volume of products manufactured (services rendered);

3. determining the profitability/unprofitability area;

4. forecasting the profit for different volumes of products sold (services rendered).

In the framework of this paper, we shall restrict ourselves with calculating the operating profit (which is the same as the sales profit, hereinafter - the profit) (Figure 2).

According to our calculations, the feasibility of setting up MSSTI will be hinged on reaching the minimum rate-ofreturn level (equation (1)) equal to $40 \%$. It is clear that the rate-of-return level is defined by the volume of sales $(N)$ and the ratio of the product price $(P r)$ and its production cost $(P C)$. As follows from the profit generation scheme (see Figure 2):

$\mathrm{Rev}=\mathrm{Rev} \cdot \mathrm{VAT}+\mathrm{C}+\mathrm{SP}$ or $\mathrm{SP}=\mathrm{Rev}(1-\mathrm{VAT})-\mathrm{C}$ 


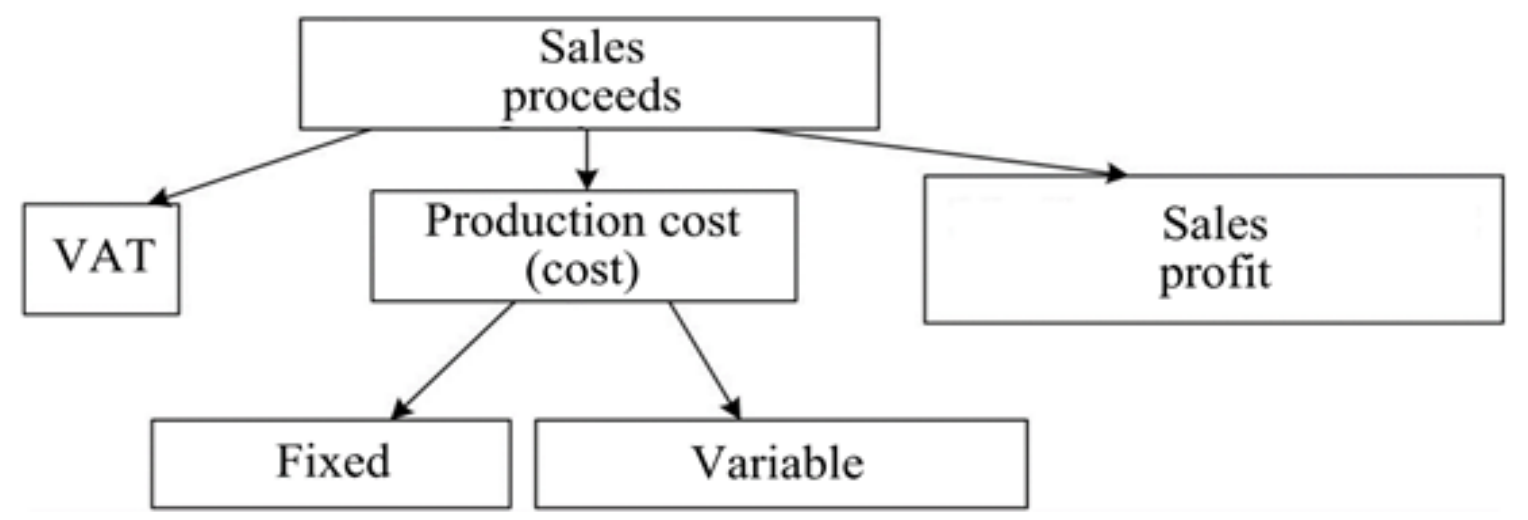

Figure 2. A profit generation scheme

where Rev is revenue generated by selling products. Hereinafter, we will not show the multiplier (1-VAT) implying that VAT is considered in equations of income calculation.

Substituting $\mathrm{SP}=\mathrm{C} \cdot \mathrm{R}$ and bearing in mind that:

$$
\operatorname{Rev}=\operatorname{Pr} \cdot N \text { and } \mathrm{C}=P C \cdot N
$$

through simple transformations we obtain the required minimum price to make selling products profitable:

$$
\mathrm{Pr}=\mathrm{PC} \cdot \frac{1+\mathrm{R}}{1-\mathrm{VAT}}
$$

As it was mentioned above, the total costs $C$ include fixed (Cfix) and variable (Cvar) costs:

$$
\mathrm{C}=\mathrm{Cfix}+\mathrm{Cvar}
$$

and provide the basis to calculate the production cost (equation (5)).

Dividing costs into fixed and variable ones allows showing the relationship between the revenue from selling products, production cost and the amount of profit generated by sales. This dependence of the profit of sales is expressed through a rate-of-return chart (Figure 3).

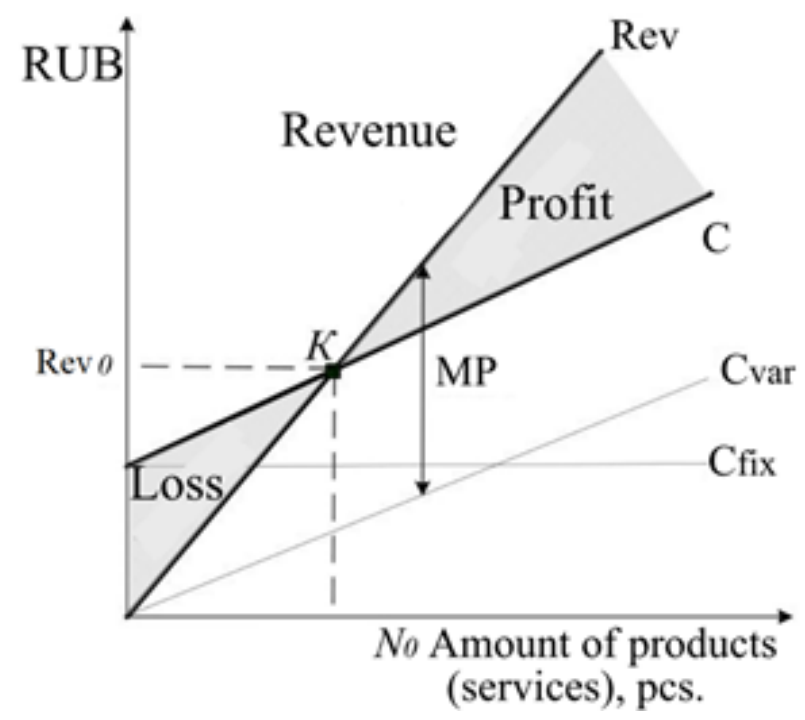

Figure 3. A rate-of-return chart: $K-$ break-even point: $\operatorname{Rev}_{0}=C$, indicates the scope of $N_{0}$ services rendered (products manufactured) to make up for the company's gross costs $\left(R e v_{0}\right.$ is the threshold revenue,

$N_{0}$ is the threshold amount of products, MP is the marginal profit
The $K$ point in Figure 3 is a break-even point; it shows the minimum revenue generated by selling products, below which the business activity is unprofitable since the production cost line is above the revenue line.

It should be noted that the difference in the slopes of the revenue (Rev) and costs $(C)$ lines is determined by the difference in the price and cost of machine-hour (margin).

The marginal analysis of using MSSTI was carried out in the Mathcad environment (Figures 4, 5) using conditions of the Komi Republic as an example for the following initial data:

- mobile laboratory at the cost of $2,786,000$ RUB (with equipment);

- $\quad$ estimated lifetime of the mobile laboratory -8 years;

- $\quad$ annual mileage $-7,500 \mathrm{~km}$;

- Value Added Tax - 18\%;

- $\quad$ number of operators - 2;

- operator salary with charges and taxes - 44,000

RUB;

- $\quad$ standard time to complete STI of a passenger car -0.76 hours;

- $\quad$ factor of MSSTI loading during working hours with account for the customers' waiting time -0.78 .

The initial data were obtained as a result of MSSTI pilot operation in the Komi Republic in (Golovko, 2012). The result of calculations showed $44 \%$ MSSTI rate of return.

As mentioned above, these results were obtained based on the calculations using the data on MSSTI pilot operation in the Komi Republic in 2012. In a competitive environment, it is important to be able to run a flexible pricing policy affecting the basic profit generation elements. Those involve the following: the service price, the number of services provided during the reporting period, components of fixed and variable costs.

In economics, the impact of relative changes in components on the profit is estimated through elasticity showing the percentage growth of the function, corresponding to increasing the argument by $1 \%$. Let us consider the indicator for the mentioned basic elements.

Increasing the service price is the most attractive way to increase the profit. At the same time, the upper price limit is restricted by market conditions, and sometimes by the effective legislation (Luo et al., 2018). 


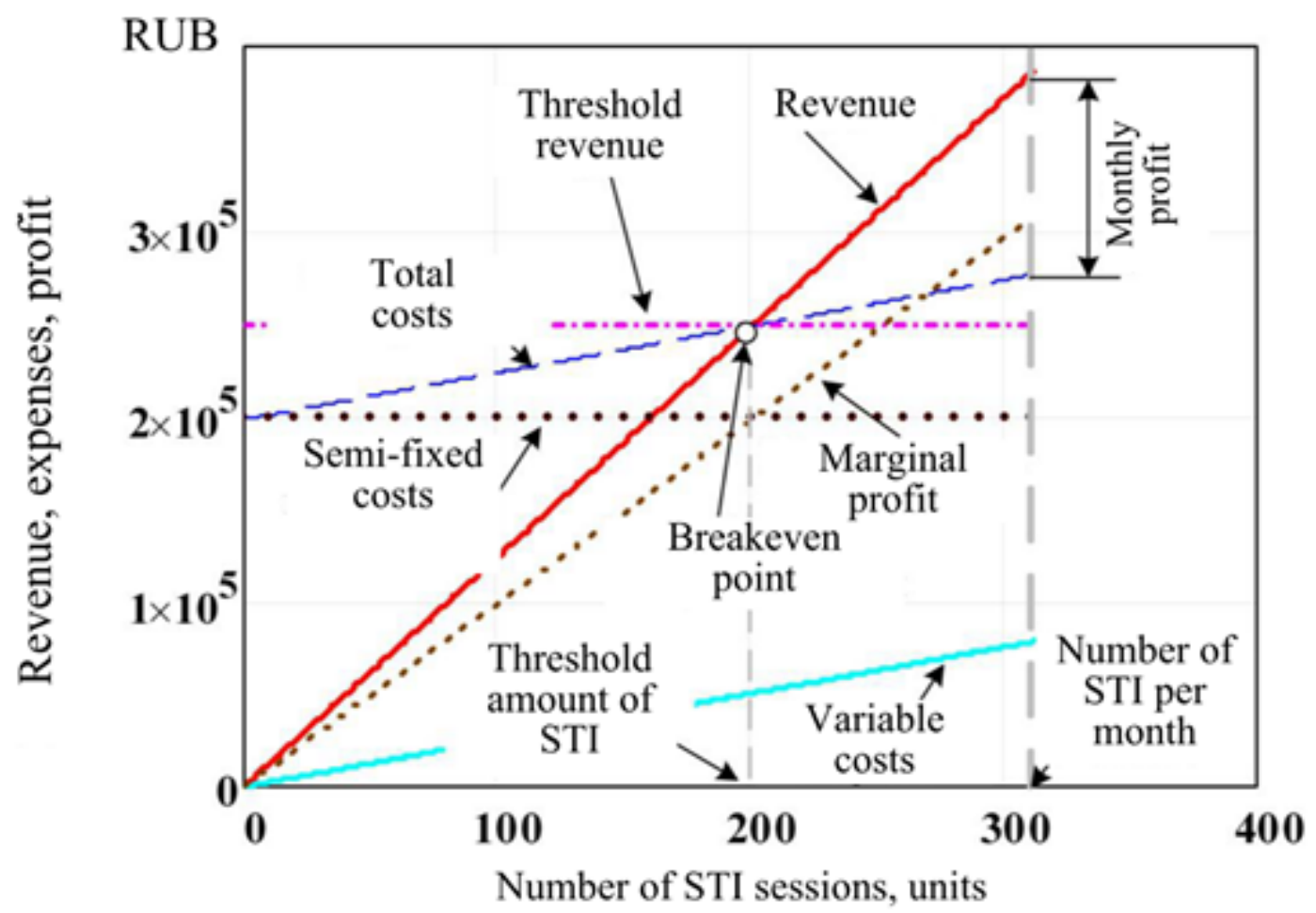

Figure 4. Results of the marginal analysis of MSSTI operation obtained in the Mathcad environment at the service price of 1,050 RUB
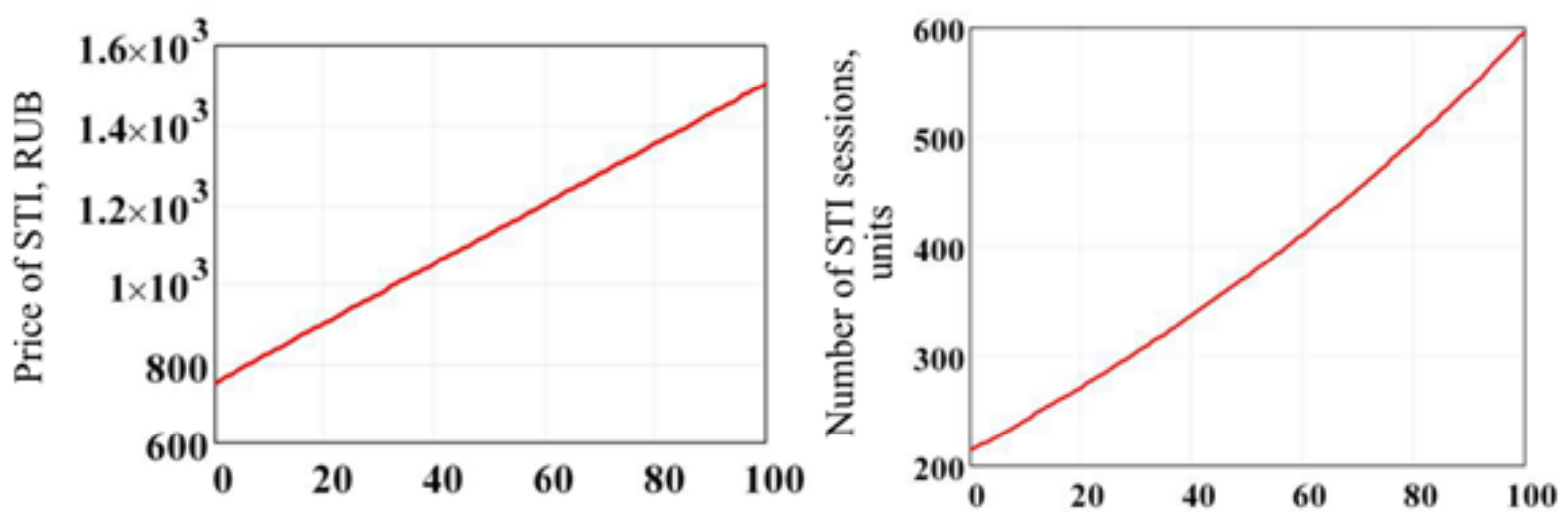

Figure 5. A dependence of the STI price (a) and the number of STI sessions (b) conducted at C = 1,050 RUB of the given rate-of-return level, calculated in the Mathcad environment

The price can be increased through expanding the list of services. For example, during STI, it is possible to issue an insurance policy or, if there is a slowdown in the flow of customers, undertake additional diagnostic, corrective maintenance and/or minor repair operations. Large companies often use decreasing product prices to strengthen their market positions which ultimately allow increasing the sales volume.

Increasing the number of STI sessions is possible through improving STI conduction (for example, getting paperwork done simultaneously with rendering technical services), reducing the customers' waiting time due to timely campaigns, improving the travel routes and choosing sites for MSSTI, etc.

Semi-fixed costs can be reduced through decreasing their components. Such decreasing is most effective when applied to overhead costs. In practice, this can be achieved through improving enterprise management, expanding the list of services provided, etc. In extreme cases, companies resort to such unpopular measure as reducing salaries and wages (Hament, Oh, 2018).

Reducing the variable cost component is possible through savings on the consumption of fuel and lubricants and improving the maintenance efficiency. When analyzing the composition of variable costs, the most effective option seems to be associated with bringing down the repair and maintenance costs.

Results of elasticity calculations are given in Table 1. The greatest influence on the profit is exerted by the following revenue components: the STI price and quantity. Fixed costs have a greater weight in the cost structure; therefore, they affect the profit value more. 
Table 1. Value of profit elasticity relative to arguments

\begin{tabular}{|l|l|l|l|l|}
\hline Function & \multicolumn{4}{|c|}{ Argument } \\
\cline { 2 - 5 } & $\begin{array}{l}\text { Semi- } \\
\text { fixed } \\
\text { costs }\end{array}$ & $\begin{array}{l}\text { Variable } \\
\text { costs }\end{array}$ & $\begin{array}{l}\text { Scope of } \\
\text { services }\end{array}$ & $\begin{array}{l}\text { Service } \\
\text { price }\end{array}$ \\
\hline Profit & -1.6 & $-0,7$ & 2.6 & 3.3 \\
\hline
\end{tabular}

\section{Conclusion}

The research results provided in the paper give a positive estimate for the economic feasibility of setting up mobile technical inspection stations. The marginal analysis methods were used to determine the limits of the economic efficiency in using STI stations, expressed through the number of STI sessions and the service price. 


\section{Architecture and Engineering Volume 3 Issue 3}

\section{References}

Azriliyan A.N. (2004). Bol'shoj ehkonomicheskij slovar' [Large economic dictionary]. Moscow: Institute of New Economics. (in Russian)

Caron, M., Mills, I. (2012). Planning and execution of tele-robotic maintenance operations on the ISS. In: Proceedings of 12th International Conference on Space Operations. Stockholm, Sweden. DOI: 10.2514/6.2012-1272635.

Dotzler, C., Botzler, S., Kierdorf, D., Lang, W. (2018). Methods for optimising energy efficiency and renovation processes of complex public properties. Energy and Buildings, 164, pp. 254-265. DOI: 10.1016/j.enbuild.2017.12.060

Frangopol, D.M., Liu, M. (2007). Maintenance and management of civil infrastructure based on condition, safety, optimization, and life-cycle cost. Structure and Infrastructure Engineering, 3 (1), pp. 29-41. DOI: 10.1080/15732470500253164

Golovko, V.A. (2012). Razrabotka proekta uchastka avtoservisa dlya okazaniya uslugi po podgotovke prohozhdeniya GTO na baze OOO "VeGo" [Developing a service station project to prepare vehicles for STI at the premises of OOO VeGo]. Syktyvkar: Saint Petersburg State University of Service and Economics, Syktyvkar Branch. (in Russian)

Hament, B., Oh, P. (2018). Unmanned aerial and ground vehicle (UAV-UGV) system prototype for civil infrastructure missions. In: Proceedings of IEEE International Conference on Consumer Electronics, ICCE 2018, pp. 1-4. DOI: 10.1109/ICCE.2018.8326346

Luo, W., Li, L., Wang, K.C.P. (2018). Automatic horizontal curve identification and measurement using mobile mapping system. Journal of Surveying Engineering, 144 (4), 04018007. DOI: 10.1061/(ASCE)SU.1943-5428.0000257.

Ratheesh, R., Vetrivelan, P. (2019). Optimal energy saving through joint deployment of relay station and sleep mode activation in 4G LTE-A network. Lecture Notes in Electrical Engineering, 493, pp. 1-12. DOI: 10.1007/978-981-10-8663-2_1.

Rubin, I., Baiocchi, A., Sunyoto, Y., Turcanu, I. (2019). Traffic Management and Networking for Autonomous Vehicular Highway Systems. Ad Hoc Networks, 83, pp. 125-148. DOI: 10.1016/j.adhoc.2018.08.018

Zeng, W., Zhang, Z. (2009). Urban drainage network analysis based on GIS. In: Proc. of International Conference on Pipelines and Trenchless Technology "Advances and Experiences with Pipelines and Trenchless Technology for Water, Sewer, Gas, and Oil Applications", 361, pp. 568-580. DOI: 10.1061/41073(361)61

Zhdanov I.A. Marzhinal'naya pribyl' [Marginal profit]. Available at: http://finzz.ru/base_knowledge/financial-analysis. (accessed on: 12.06.2018) (in Russian) 